\title{
Physical Therapy with Drug Treatment in Bell Palsy A Focused Review
}

\author{
Margarida Ferreira, $\mathrm{PhD}$ \\ Elisa E. Marques, $\mathrm{PhD}$ \\ José A. Duarte, $\mathrm{PhD}$ \\ Paula C. Santos, PhD
}

\begin{abstract}
The physical therapy (PT) associated with standard drug treatment (SDT) in Bell palsy has never been investigated. Randomized controlled trials or quasirandomized controlled trials have compared facial PT (except treatments such as acupuncture and osteopathic) combined with SDT against a control group with SDT alone. Partic-ipants included those older than 15 yrs with a clinical diagnosis of Bell palsy, and the primary outcome measure was motor function recovery by the House-Brackmann scale. The methodologic quality of each study was also independently assessed by two reviewers using the PEDro scale. Four studies met the inclusion criteria. Three trials indicate that PT in association with SDT supports higher motor function recovery than SDT alone between 15 days and $1 \mathrm{yr}$ of follow-up. On the other hand, one trial showed that electrical stimulation added to conventional PT with SDT did not influence treatment outcomes. The present review suggests that the current practice of Bell palsy treatment by PT associated with SDT seems to have a positive effect on grade and time recovery compared with SDT alone. However, there is very little quality evidence from randomized controlled trials, and such evidence is insufficient to decide whether combined treatment is beneficial in the management of Bell palsy.
\end{abstract}

Key Words: Rehabilitation, Facial Muscle Recovery, House-Brackmann, Randomized Controlled Trial, Physical Therapy

Idiopathic peripheral facial nerve palsy or Bell palsy (BP) refers to an acute onset of lower motor neuron type of facial paralysis (complete palsy) or paresis (partial palsy), resulting in an inability to control facial muscles on the affected side. BP is the most frequent form of peripheral palsy of the facial nerve, and the reported annual instance is between 11 and 53.3 new cases per 100,000 persons. ${ }^{1,2}$ It leads to considerable disturbance in social activities. ${ }^{3}$ The etiology of $\mathrm{BP}$ is unknown, but it is widely accepted as being due to the reactivation of latent herpes simplex type 1 virus within geniculate ganglion, followed by the ethiopathologic mechanism that involves inflammation and entrapment of the nerve at the meatal foramen that leads to demyelination of the axons and possible ischemia by disruption of blood supply. ${ }^{4,5}$ The aims of any treatment in acute-stage BP are to promote speedy recovery and prevent sequelae. Thus, the most effective evidence-based treatment that entails 
the fewest side effects or risks should be prescribed. Considerable knowledge has been accumulated concerning the significance of pharmacologic treatment based on the presumed pathophysiology of BP, namely, inflammation and viral infection. On the basis of evidence, some physicians prescribe corticosteroids as a primary treatment because of their potential to reduce swelling and inflammation, whereas the aim of antiviral treatment is to inhibit herpes simplex type 1 virus replication through viral DNA polymerase. Several studies have demonstrated somewhat conflicting results about the effectiveness of corticosteroids only or combined with antiviral treatment. The meta-analysis by Nunthavaj et al. ${ }^{6}$ suggests that corticosteroids combined with antiviral treatment may lead to slightly higher recovery rates at 3 and 6 mos compared with treating with corticosteroids only, although this difference is not statistically significant. Corticosteroids remain the strongest evidence-based monotherapy treatment, whether compared with placebo or antiviral treatment. ${ }^{6,7}$ On the other hand, one systematic review ${ }^{8}$ included three studies with 117 patients who demonstrated no benefit from using corticosteroids only compared with placebo/vitamin. The American College of Neurology currently recommends the use of oral corticosteroids only. ${ }^{9}$

For the past decades, some methods and physical agents of facial physical therapy (PT), such as functional neuromuscular reeducation associated with or without mirror, mime therapy, electrical stimulation, surface electromyography biofeedback, and video self-modeling, have been used to treat facial paralysis, but the significance of PT is controversial. ${ }^{10-12}$ Most previous studies evaluated the effects of PT or drug therapy only. Thus, the combined effect of PT with corticosteroids and/or antivirals on patients' recovery rates has been poorly investigated. In addition, it should be highlighted that BP has a high rate of spontaneous recovery, thus making it difficult to establish a strong cause-effect association between treatment and recovery, even in controlled trials. Peitersen ${ }^{13}$ suggested a favorable prognosis of spontaneous recovery within $3 \mathrm{wks}$ in $85 \%$ of patients, and $70 \%$ had a complete recovery within 6 mos. However, patients with inappropriate treatment may experience longstanding paralysis and develop sequelae, contractures, partial recovery of motor function, and synkinesis, affecting $31 \%$ of BP patients. ${ }^{14}$

The conclusion of the literature review was that, although standard drug treatment (SDT) seems to reduce edema and secondary inflammation damage, it does not influence the amount of long-term damage. As the only alternative to no treatment, PT seems to be effective in improving facial expression and function. Strategies of PT have been developed to control the symmetry of the face, through slow movements and voluntary control of synkinesis, particularly with specific exercises. The central question in this research is, "Do PT and SDT have positive effects on grade and time recovery in BP?" Given the emergence of this clinical practice and lack of evidence of the benefits, this is the first systematic review to present the evidence for prescribing PT associated with SDT.

\section{METHODS}

\section{Criteria for Considering Studies for This Review}

\section{Studies and Participants}

A study was included in the review only when the following criteria were met: (1) there were randomized trials (RCTs) or quasi-RCTs, (2) the study population consisted of patients diagnosed with BP of all degrees of severity, (3) the efficacy of PT plus drugs treatment was evaluated, (4) there were at least 15 days of follow-up, (5) the outcome measure was motor function recovery by a recognized scoring system such as the House-Brackmann (HB) facial grading system, ${ }^{15,16}$ (6) there was a comparative control group (CG), and (7) it included adults older than 15 yrs. The authors did not include studies on pregnant women, patients experiencing recurrent or bilateral BP, and studies comparing PT or drugs therapy only. No language restrictions were used.

\section{Types of Interventions}

Included studies compared interventions with any PT (except acupuncture and osteopathic) combined with SDT (corticosteroids and/or antiviral agents) against a CG. The accepted intervention in the comparison group was SDT only or SDT (similar in the experimental group [EG]) plus a distinctive PT to assess which PT technique is the most beneficial. PT in BP can include functional neuromuscular reeducation with or without mirror, mime therapy, video self-modeling, electromyography biofeedback, and electrical stimulation with or without thermal or massage agents.

SDT was accepted if administered orally and started immediately after the diagnosis of BP..$^{9,17,18}$

\section{Types of Outcome Measures}

The primary outcome of the present study was complete or partial facial muscle recovery, defined by HB grade 1 or 2 . This scale analyzes the 
symmetry, synkinesis, stiffness, and global mobility of the face. It is divided into six categories (normal, mild dysfunction, moderate dysfunction, moderately severe dysfunction, severe dysfunction, and total paralysis) and is a 1 - to 6 -point scale with 6 representing total paralysis. ${ }^{15,16}$

Secondary outcome measures were adverse events (side effects of interventions); compound motor action potential amplitude and percentage activity as measured in the orbicular oculi and frontal and orbicular oris muscles, the both sides of the face [(electroneurography $(\%)=100-100 *$ (amplitude on the affected side/amplitude on the healthy side)]; no residual symptoms (synkinesis, hemifacial spasm, contractures, epiphory); and Sunnybrook facial grading system (SB). The SB system has three components of facial asymmetry: resting asymmetry (scored from 0/asymmetry to 4/symmetry), symmetry of voluntary movement (0/asymmetry, $5 /$ symmetry), and synkinesis (0/better, 3/worst). ${ }^{19}$ A total score of 100 points represents normal facial symmetry.

\section{Search Methods for Identification of Studies}

The search strategy was applied to the following databases: MEDLINE, Academic Search Complete, MedicLatina, CINAHL, SPORTDiscus, Scopus, and PEDro from their inception to August 1, 2013. The search method incorporated National Library of Medicine Medical Subject Headings, ${ }^{20}$ combining the following terms: (1) type of disease, "idiopathic facial palsy" or "facial paralysis" or "Bell's palsy," and (2) types of intervention, "physical therapy" or "physiotherapy" or "mime therapy" or "exercise movement techniques" or "facial exercises" or "facial expression" or "physical rehabilitation" or "Biofeedback" or "electrical stimulation" or "massage" and ["drug therapy" or "anti-viral agents" or "acyclovir" or "valacyclovir" or "famciclovir" or "antiinflammatory agents" or "cortisone" or "prednisone" or "corticosteroids" or "steroids"].

\section{Selection of Studies and Data Extraction}

Abstracts and full texts identified by computerized database searches were screened by two reviewers (MF, JD), using predetermined eligibility criteria to ascertain potentially relevant trials to be included in the review, as defined in the National Health and Medical Research Council classification guidelines. ${ }^{20,21}$ All relevant information was collected in data extraction form, which included the following: study design, authors and year of publication, country and setting, sample size, patient demographics, number of patients in each treatment group, type of antiviral and/or steroids used and dose, type and frequency of PT, length of followup, type of facial muscle recovery outcome scale used, definition for facial recovery, proportion of patients with facial recovery at each follow-up time point, and methodologic quality of included studies. Disagreements regarding trial eligibility were

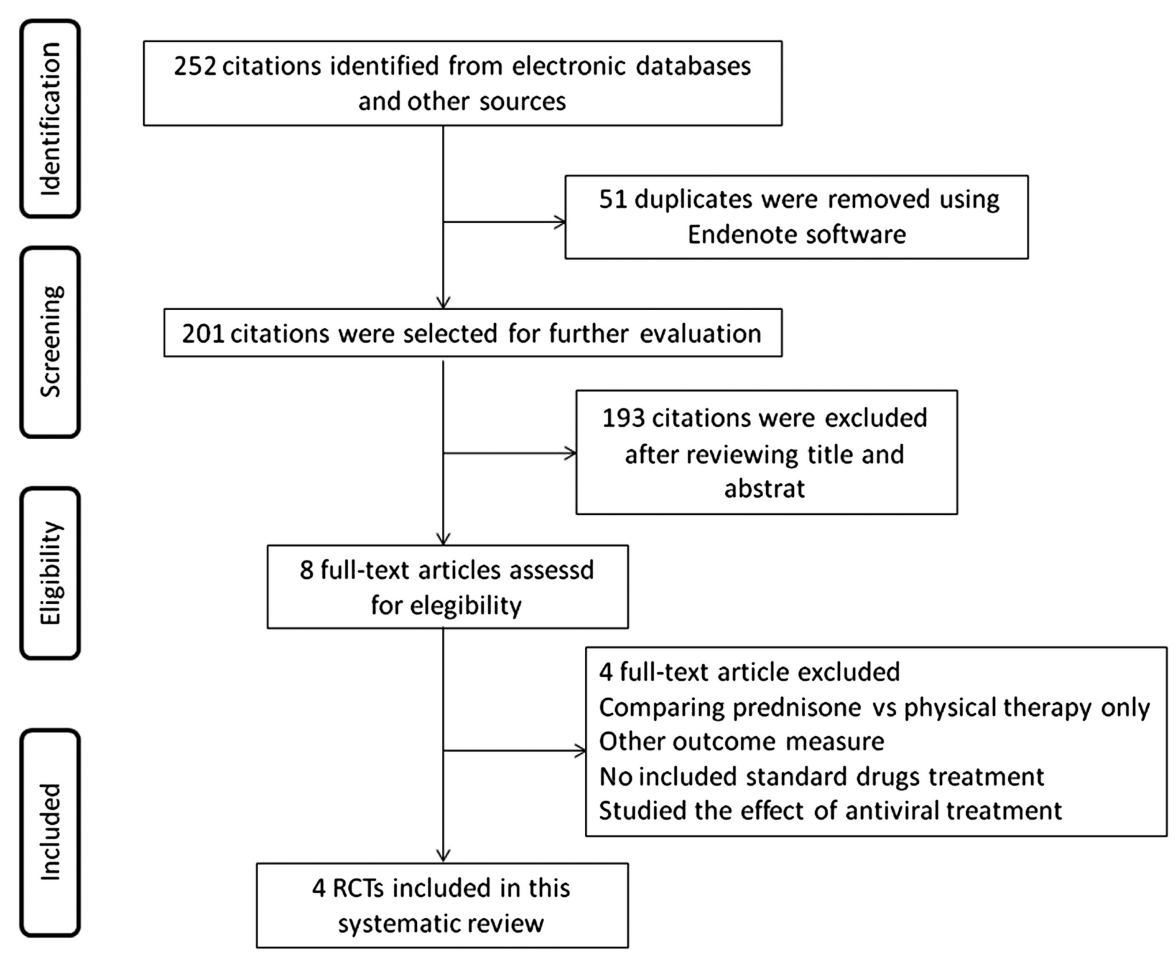

FIGURE 1 Flow diagram of the study selection process. 
resolved by discussion and consultation by a third reviewer (ME).

\section{Assessment of Methodologic Quality}

The PEDro scale was used to rate the methodologic quality of each study. The scale contains 11 items, of which ten items assess internal validity. ${ }^{22,23}$ One criterion was omitted among the studies (eligibility criteria), because such criterion refers to the generalization of the results. Each item was graded 0 or 1 (point), with a maximum score of 10 points. PEDro scores were interpreted as follows: a score of 9 or more indicated excellent methodologic quality, 6-8 was good methodologic quality, 4-5 was fair methodologic quality, and $<4$ was poor methodologic quality. Two reviewers (MF, JD) assessed quality independently. Any disagreement between the two reviewers was discussed and resolved by consensus with a third author (EM).

\section{RESULTS}

\section{Description of Studies \\ Selected Studies}

The search strategy retrieved 252 abstracts (Fig. 1). As some studies were found in more than one database, duplicates were removed. A total of 244 studies were excluded because they did not match the inclusion criteria. Of these, eight trials were identified as highly relevant, although four were subsequently excluded: one study ${ }^{24}$ compared the intervention with prednisone alone vs. PT alone, another study ${ }^{25}$ used different outcome measures, another study ${ }^{26}$ did not include SDT, and the last analyzed the effect of antiviral treatment. ${ }^{27}$ Four studies satisfied the inclusion criteria and were included in the current review.

\section{Included Studies}

In total, four studies ${ }^{28-31}$ were included in the systematic review (Table 1). Of these, three studies ${ }^{28-30}$

TABLE 1 Characteristics of included studies

\begin{tabular}{|c|c|c|}
\hline Study & Country, Setting & Participants \\
\hline Nicastri et al. ${ }^{28}$ (2013) & $\begin{array}{l}\text { Italy University Hospital } \\
\text { "Umberto I" }\end{array}$ & $\begin{array}{l}\text { Total of } 87 \text { patients with severe grade (HB } \geq \text { IV) } \\
\text { on the tenth day after the onset of palsy; } \\
\text { follow-up, } 6 \text { mos; CG, } 48 \text { patients ( } 22 \text { men, } \\
26 \text { women); age, } 51.3 \text { yrs; EG, } 39 \text { patients } \\
\text { ( } 22 \text { men, } 17 \text { women); age, } 47.1 \text { yrs }\end{array}$ \\
\hline Barbara et al. ${ }^{29}(2010)$ & $\begin{array}{l}\text { Italy University Hospital } \\
\text { "Sant'Andrea" }\end{array}$ & $\begin{array}{l}\text { Total of } 20 \text { patients with moderate-to-severe } \\
\text { grade (HB } \geq 3 \text { ) on the third day after onset, } \\
\text { follow-up of } 2 \text { wks; CG (nonrehabilitation), } \\
11 \text { patients (five men, six women); age, } 42 \text { yrs; } \\
\text { EG (rehabilitation), nine patients (five men, } \\
\text { four women); age, } 35 \text { yrs }\end{array}$ \\
\hline Penteado et al. ${ }^{30}$ (2009) & $\begin{array}{l}\text { São Paulo (South America) } \\
\text { Hospital University }\end{array}$ & $\begin{array}{l}\text { Total of } 20 \text { patients with moderate-to-severe } \\
\text { grade (HB } \geq \text { III-V) on the fourth mo of the } \\
\text { episode of BP were followed for } 1 \text { yr; CG, } \\
\text { ten patients (18-60 yrs); EG, ten patients } \\
\text { (18-60 yrs) }\end{array}$ \\
\hline Alakram et al. ${ }^{31}(2010)$ & $\begin{array}{l}\text { South Africa Hospital } \\
\text { Complex (three hospitals) }\end{array}$ & $\begin{array}{l}\text { Total of } 16 \text { patients in early stages of BP, } \\
\text { follow-up of } 3 \text { mos; CG, eight patients } \\
\text { (three men, five women); age, } 41.4 \text { yrs; } \\
\text { EG, eight patients (five men, three } \\
\text { women); age, } 3.6 \text { yrs }\end{array}$ \\
\hline
\end{tabular}


evaluated SDT (corticosteroids + antiviral agents) plus PT vs. SDT alone. The other study ${ }^{31}$ evaluated a monotherapy drug (prednisolone) plus conventional PT vs. prednisolone plus conventional PT and electrical stimulation.

The four trials included an overall sample of 143 patients (between 16 and 87 patients). The length of follow-up varied between studies and ranged from 2 wks to 12 mos. Trials were conducted in three countries and on three continents. Three studies ${ }^{28,29,31}$ were published in English, and one study ${ }^{30}$ was published in French.

The study by Nicastri et al. ${ }^{28}$ was designed for 6 mos, was single-blind, and was an RCT. It included 87 patients with BP, distributed in two treatment groups: an EG (39) received SDT (prednisone + valacyclovir) combined with PT, and the CG (48) received SDT. The eligibility criteria were as follows: age between 15 and 70 yrs, unilateral BP clinically diagnosed, and severe (grades IV-VI) facial palsy assessed by HB on the tenth day after the initial symptoms of BP. Both groups were treated with oral prednisone (1 mg/day for 10 days) plus valacyclovir (500 mg three times per day for 6 days). In addition, the EG was treated with a neuromuscular retraining program that consisted of facial muscle physiology and massage education, active motion exercises with or without mirror feedback, stretching, and specific facial exercises. Each patient of EG was treated in the outpatient clinic by means of individual sessions lasting 45 mins each, twice a week for the first 3 mos and once a week thereafter, until the follow-up was completed. All patients were assessed by HB on their first visit to the clinic, 10 days thereafter, and then monthly until the end of follow-up (6 mos).

Barbara et al. ${ }^{29}$ published a study of a randomized trial: 20 patients with moderate- to severe-grade

\begin{tabular}{|c|c|c|}
\hline Interventions & Outcome & Results/Conclusions \\
\hline $\begin{array}{l}\text { CG: patients who received only SDT (oral } \\
\text { prednisone of } 1 \mathrm{mg} / 10 \text { days + valacyclovir } \\
\text { of } 500 \mathrm{mg} \text { three times a day for } 6 \text { days). } \\
\text { EG: patients who received the same SDT } \\
\text { plus PT (neuromuscular retraining program } \\
\text { with or without mirror feedback; individual } \\
\text { sessions lasting } 45 \text { mins each/two times a } \\
\text { week for the first } 3 \text { mos and once a week } \\
\text { thereafter, until the follow-up was completed } \\
\text { or at the end of the } 6 \text { mos). }\end{array}$ & $\begin{array}{l}\text { The primary outcome was the } \\
\text { HB-FGS (reaching a grade } \\
\text { of II or less). The secondary } \\
\text { outcomes were the time to } \\
\text { reach a HB-FGS grade of II } \\
\text { or less, the differences over } \\
\text { time in the mean SB-FGS } \\
\text { total score, and the proportion of } \\
\text { patients having a synkinesis } \\
\text { subscore of } 0 \text { (i.e., no synkinesis). }\end{array}$ & $\begin{array}{l}\text { The results demonstrated that } \\
\text { the EG experienced a } \\
\text { significant effect in grade and } \\
\text { time to recovery only among } \\
\text { patients presenting with } \\
\text { severe facial palsy (HB grade } \\
\text { V/VI). The reduction of } \\
\text { synkinesis was not significant } \\
\text { between the groups. }\end{array}$ \\
\hline $\begin{array}{l}\text { CG: patients were submitted to SDT (oral } \\
\text { prednisolone of } 40 \text { mg/day for } 10 \text { days and } \\
\text { then tapered within the next } 5 \text { days + } \\
\text { acyclovir of } 400 \mathrm{mg} \text { three times per day } \\
\text { for } 15 \text { days). EG: patients received the } \\
\text { same SDT and Kabat rehabilitation or } \\
\text { proprioceptive neuromuscular } \\
\text { facilitation (stretching, maximal resistance, } \\
\text { manual contact, verbal input). }\end{array}$ & $\begin{array}{l}\text { HB-FGS (grades I and II) and } \\
\text { electroneurography (amplitude } \\
\text { of the compound motor action } \\
\text { potential); normal range was } \\
\text { considered to be between } \\
2 \text { and } 4.5 \mathrm{mV} \text {. }\end{array}$ & $\begin{array}{l}\text { Kabat rehabilitation patients } \\
\text { achieved a better and faster } \\
\text { recovery in comparison } \\
\text { with nonrehab patients, } \\
\text { in early stages. }\end{array}$ \\
\hline $\begin{array}{l}\text { CG: received SDT (oral prednisone of } 1 \mathrm{mg} / \text { day } \\
\text { for } 15 \text { days + valacyclovir of } 500 \text { mg three } \\
\text { times a day for } 5 \text { days). EG: patients received } \\
\text { the same SDT and rehabilitation facial or } \\
\text { Chevalier method, which consisted of analytic } \\
\text { muscle exercises and undesirable movement } \\
\text { inhibition by stretching, for } 15 \text { mins, two times } \\
\text { per day and five-to-ten repetitions for each } \\
\text { exercise, from days } 1 \text { to } 15 \text { after symptom onset. }\end{array}$ & $\begin{array}{l}\text { HB-FGS (grades I } \\
\text { and II), SB-FGS }\end{array}$ & $\begin{array}{l}\text { The facial rehabilitation } \\
\text { method described by } \\
\text { Chevalier showed } \\
\text { improvement in function } \\
\text { recovery than CG. }\end{array}$ \\
\hline $\begin{array}{l}\text { CG: patients were treated with drug } \\
\text { monotherapy (oral prednisolone of } 2 \text { mg } \\
\text { daily) weaned off within } 2 \text { wks and combined } \\
\text { conventional PT ( } 5 \text { mins of hot packs, } \\
10 \text { mins of massage, and ten repetitions } \\
\text { of exercises once a week/home exercise). } \\
\text { EG: patients received the same drug } \\
\text { monotherapy and conventional PT with } \\
\text { electrical stimulation ( } 30 \text { mins/TENS unit). }\end{array}$ & $\begin{array}{l}\text { HB-FGS (recovery } \\
\text { defined, } 80 \% \text { ) }\end{array}$ & $\begin{array}{l}\text { The improved percentage } \\
\text { of HB-FGS in the EG } \\
\text { was not significant } \\
\text { compared with the CG. }\end{array}$ \\
\hline
\end{tabular}


(HB $\geq$ III-VI) early-stage BP who submitted to SDT (prednisolone + acyclovir) for 15 days were included. Drugs treatment was immediately started, combining oral prednisolone $(40 \mathrm{mg} /$ day for 10 days and then tapering off within the next 5 days) plus acyclovir (400 mg three times per day for 15 days). After that, they were divided into two groups. The rehabilitation group (rehab group) of nine patients underwent Kabat rehabilitation with one session per day for 6 days, sustained for 15 days. The nonrehabilitation group (nonrehab group) of 11 patients did not submit to physical rehabilitation. Kabat rehabilitation or proprioceptive neuromuscular facilitation started from day 4 after BP onset and included stretching, maximal resistance, manual contact, and verbal input. This method considers the harmony, coordination, and optimal strength of body movements through a global pattern. The evaluation was carried out by measuring the amplitude of the compound motor action at days 4,7 , and 15 after onset of BP as well as by observing grade HouseBrackmann within 3, 4, 7, and 15 days.

Penteado et al..$^{30}$ had 20 patients with moderateto-severe grade ( $\mathrm{HB} \geq \mathrm{III}-\mathrm{V})$ on the fourth month after onset of BP, who were followed for $1 \mathrm{yr}$. All patients received SDT oral prednisone $(1 \mathrm{mg} / \mathrm{kg} /$ day for 15 days) plus valaciclovir (500 mg three times per day for 5 days). The $\mathrm{EG}$ included ten patients treated according to the facial rehabilitation method described by Chevalier between the 1st and 15th days after the installation of BP and having developed sequelae during their recovery. Facial rehabilitation consisted of analytic muscle exercises on the palsy face and inhibition of undesirable movements by stretching. The $\mathrm{CG}$ received a nonrehabilitation facial. All patients were evaluated weekly during the first month and then monthly until the end of the study by HB and SB scales.

The study conducted by Alakram and Puckree ${ }^{31}$ had 16 patients with BP with less than 30-day duration, randomized into two intervention groups with eight patients each. Both groups were treated with oral prednisolone $(2 \mathrm{mg} / \mathrm{kg}$ daily, weaned off within 2 wks). The researcher treated each patient in both groups (CG and EG) with 5 mins of heat, 10 mins of massage, and ten repetitions of exercises once a week, and each patient was also given an illustrated home exercise handout with instructions: ten repetitions of each exercise, three times daily. The EG also received electrical stimulation of the facial muscles (30 mins/pulse and frequency of $10 \mathrm{~Hz} /$ pulse width and duration of $10 \mu \mathrm{secs})$. All patients were objectively evaluated with the HB scale until recovery, for a maximum of 3 mos after onset of BP.

\section{Methodologic Quality of the Studies}

PEDro scores ranged between 2 and 8 (Table 2), with one study ${ }^{28}$ considered to have good methodologic quality (i.e., PEDro score of 6-8). All studies ${ }^{28-31}$ were conducted with no blind patients, therapists, and concealed allocation, which reduced the maximum score achieved. On the other hand, all studies ${ }^{28-31}$ satisfied the criteria of baseline similarity between groups and point estimates and variability. Three studies ${ }^{28-30}$ observed the follow-up of greater than $85 \%$, and two studies ${ }^{30,31}$ did not use random allocation.

\section{Effects of Interventions}

\section{Primary Outcome Measure}

All studies reported satisfactory recovery for PT and medical treatment. Nicastri et al. ${ }^{28}$ showed that the EG (PT plus SDT) had a significant effect in function recovery $(P=0.038)$ and time of recovery $(P=0.044)$ compared with the CG (SDT) on patients with $\mathrm{HB}$ grade V/VI, at the end of the 6-mo followup period.

The study by Barbara et al. ${ }^{29}$ showed that the rehabilitation group (Kabat rehabilitation combined with SDT) had significant improvement only at day

TABLE 2 Methodologic quality of studies

\begin{tabular}{|c|c|c|c|c|c|c|c|c|c|c|c|c|}
\hline \multicolumn{13}{|c|}{ PEDro Criterion } \\
\hline Study & 1 & 2 & 3 & 4 & 5 & 6 & 7 & 8 & 9 & 10 & 11 & Total/10 \\
\hline Nicastri et al. ${ }^{28}(2013)$ & 1 & 1 & 0 & 1 & 0 & 0 & 1 & 1 & 1 & 1 & 1 & $7 / 10$ \\
\hline Barbara et al. ${ }^{29}(2010)$ & 1 & 1 & 0 & 0 & 0 & 0 & 0 & 1 & 0 & 1 & 1 & $4 / 10$ \\
\hline Penteado et al. ${ }^{30}$ (2009) & 1 & 0 & 0 & 1 & 0 & 0 & 0 & 1 & 0 & 1 & 1 & $4 / 10$ \\
\hline Alakram et al. ${ }^{31}(2010)$ & 1 & 0 & 0 & 0 & 0 & 0 & 0 & 0 & 0 & 1 & 1 & $2 / 10$ \\
\hline
\end{tabular}

PEDro criteria: (1) eligibility criteria, (2) random allocation, (3) concealed allocation, (4) baseline comparability, (5) blind subjects, (6) blind therapists, (7) blind assessors, (8) follow-up > 85\%, (9) intention-to-treat analysis, (10) between-group comparisons, and (11) point estimates and variability.

Item scoring: 1, present; 0 , absent. Criterion 1/eligibility criteria does not contribute to total score. 
$15(P=0.028)$ compared with the nonrehabilitation group (SDT). At day 15, the worst grade of paralysis was HB III and affected $44 \%$ of the rehab group, whereas $10 \%$ of patients in the nonrehab group were affected by HB V. Conversely, HB grade I (normal function) was observed in $22 \%$ of the rehab group and in $20 \%$ of the nonrehab group.

The Penteado et al. ${ }^{30}$ study showed better facial recovery of motor function (HB, 87 values or grades I and II) with the Chevalier method plus SDT compared with SDT (HB, 69 or grades III and IV).

Alakram and Puckree ${ }^{31}$ compared two interventions and reported rate recovery of motor function in the $\mathrm{CG}$ between $17 \%$ and $50 \%$ with a mean of $30 \%$, whereas that for the $\mathrm{EG}$ ranged from $17 \%$ to $75 \%$ with a mean of $37 \%$. The difference between the groups was not statistically significant $(P=0.36)$.

\section{Secondary Outcome Measure}

The Nicastri et al. ${ }^{28}$ study reported a significant difference between two groups for SB final scores: 60 and 79 values for the CG and EG, respectively $(P=0.021)$.

The Barbara et al. ${ }^{29}$ study showed no significant variation in compound motor action potential amplitude.

The Penteado et al..$^{30}$ study revealed a difference between groups for SB final scores: 89 values for the Chevalier method plus medical treatment group and 69 values for medical treatment.

\section{Residual Symptoms}

Nicastri et al. ${ }^{28}$ demonstrated that synkinesis was found in 25 patients (29\%), and in most cases, it started after the fourth month of follow-up. There were no differences between the two treatment groups in the proportion of patients with a synkinesis subscore of 0 at the end of the study period.

The Penteado et al. ${ }^{30}$ study also showed that sequelae were developed approximately the fourth month after onset of palsy, in both groups.

Three studies ${ }^{29-31}$ did not evaluate synkinesis.

\section{Adverse Events}

All studies did not report side effects of pharmacologic treatment, but Sullivan et al. ${ }^{18}$ reported peptic ulceration, hypertension, and state-ofconfusion effects.

\section{DISCUSSION}

Many physicians prescribe antiviral and steroid drugs to treat $\mathrm{BP}$, despite the unclear benefits of antiviral therapy. ${ }^{32}$ Recent evidence from large RCTs indicates that the complete recovery rate with oral prednisolone is approximately 85\%-94\% within 9-12 mos. ${ }^{18,33}$ In the present review, all studies ${ }^{28-31}$ had anti-inflammation interventions (prednisone or prednisolone), administered within 48-72 hrs of the onset of BP. In opposition to medical treatment, PT is an alternative and is one of the most commonly used in clinical practice. This review included modalities of facial rehabilitation in the form of $\mathrm{Kabat}^{29}$ and Chevalier, ${ }^{30}$ electrical stimulation, ${ }^{31}$ neuromuscular retraining ${ }^{28}$ with or without massage, and hot pack. The efficacy of facial rehabilitation has been shown in patients with permanent sequelae or long-standing facial paresis (at least 9 mos) by several observational studies. ${ }^{34-37}$ In contrast, the efficacy of facial rehabilitation in early/acute stages is more complex to calculate because of the high rate of spontaneous recovery. ${ }^{13}$ Presently, there are scarce studies about conservative treatment in the early stage of $\mathrm{BP}^{38,39}$ Three systematic reviews ${ }^{11,12}$ demonstrated that the ideal modality of PT has not yet been established or that no clear consensus exists. According to the previous literature, reviews focused on the monotherapy of SDT or PT effects of interventions, and so the combined therapy effects of interventions remain unknown.

In the present systematic review, three studies ${ }^{28-30}$ indicate that facial rehabilitation associated with SDT is slightly superior in recovery of motor function than SDT alone. One $\mathrm{RCT}^{28}$ showed a significant effect on grade and time to recovery in patients presenting with severe $\mathrm{BP}(\mathrm{HB} \geq \mathrm{IV})$ compared with SDT alone. In addition, through secondary outcomes, two studies ${ }^{28,30}$ reported significant facial symmetry by Sunnybrook with the neuromuscular retraining and rehabilitation method described by Chevalier. Only one study ${ }^{28}$ showed that combined treatments are effective in fighting synkinesis. On the other hand, one study ${ }^{31}$ did not find the kind of technique in PT for the recovery motor function of BP; this study concluded that electrical stimulation did not greatly influence the recovery rate of BP.

Thus, the studies covered in this systematic review support improvements with respect to drugs treatment, which might include the following:

(1) Corticosteroids reduce the inflammatory process in BP, and this facilitates remyelination of the facial nerves. This theory made good physical sense based on the length of the canal and relatively small caliber and subsequent decompression of the nerve. ${ }^{6,18}$

(2) The addition of antiviral treatment such as acyclovir or valacyclovir is aimed at the eradication of herpes simplex type 1 infection. ${ }^{6,7}$ 
This prescription therapy is based on primary etiology; it is quite plausible when it involves the viral agents' herpes simplex type 1 or varicella-zoster virus.

In addition, the possible explanations for the incremental effects of PT might include the following:

(1) External feedback techniques such as specific instructions and mirror are adjuvant techniques to control the correct pattern of responses that the patient will learn to self-regulate. ${ }^{40}$

(2) Soft-tissue mobilization and hot pack preserve muscle trophism, increase circulation, and reduce involuntary contraction induced by relaxation. ${ }^{14}$

(3) Electrical stimulation has been discouraged in the early stages of BP to avoid potential interference with neural regeneration. ${ }^{39}$ It is difficult to produce an isolated contraction of the facial muscles using electrical stimulation due to their small size and close proximity to each other. The contraction produced causes mass action, which reinforces abnormal motor patterns and can be painful. ${ }^{41,42}$

(4) The neuromuscular rehabilitation, Kabat and Chevalier rehabilitation, included the active assistive movement to guide the movement pattern and to promote axonal regeneration by improving the neuronal connection and facilitating new motor patterns. ${ }^{43}$ Owing to the lack of somatosensory afferents that constitute the main intrinsic feedback in relearning movements is particularly important in facilitating the proprioceptive inputs by PT techniques. ${ }^{44}$

(5) The stretching can influence the lengthtension relationship of muscles, avoiding mass movement patterns and synkinesis. ${ }^{44}$

These combined modalities of BP should be centralized in the degenerative lesion of the facial nerve, which may be the most important risk factor for incomplete recovery. The time course for improvement and the extent of recovery are significantly different in patients presenting with an incomplete (paresis) at the onset of BP. Patients with incomplete BP should start to improve their facial function within 1-2 wks after onset of BP and are expected to recover completely within $3 \mathrm{wks}^{13}$ These patients have a spontaneous recovery of BP; it does not seem that any treatment adds benefits because of the only partial degeneration and blocking of nerve conduction (neuropraxia). ${ }^{13}$ One study ${ }^{31}$ included patients with slight dysfunction in the onset of BP (corresponding $\mathrm{HB}=\mathrm{II}$ ), which showed improvement in function recovery after 2 wks, and no significant differences between the groups. On the other side, in the patients' subgroup with moderate-to-complete paralysis (corresponding $\mathrm{HB}$ grade $\geq$ III) at the onset of $\mathrm{BP}$, complete recovery is more uncertain. Optimum therapy remains a crucially important issue for the $30 \%$ of patients who experience a varying degree of complications, including permanent paresis, pain, and synkinesis, which can be highly stressful. ${ }^{45}$ Three studies $^{28-30}$ demonstrate that PT plus SDT approaches seem to be more effective in the severe and early/acute stages of BP.

\section{Limitations}

To the authors' knowledge, this is the first systematic review examining the effectiveness of combined PT with SDT in the early stage of BP.

First, as with any systematic review, there is the potential for selection bias; however, the authors used an ample search strategy in which the authors included publications in any language as well as independent reviewers; exclusion criteria were clearly documented.

Second, the PEDro scores were lowered by a lack of insufficient randomization and allocation concealment; appropriate blinding of patients, therapists, and assessors; and substantial losses in intention-to-treat analysis. Third, there was heterogeneity among studies, particularly the sample size, grades severity at baseline, time of duration of the intervention, delay in receiving treatment of $\mathrm{PT}$, and different types of modalities. Finally, a few studies were included. This diversity prevented us from conducting a meta-analysis and highlights the need for further research.

\section{CONCLUSIONS}

The present review suggests that the current practice of BP treatment by PT associated with SDT seems to have a positive effect on grade and time recovery compared with SDT alone. However, there is very little quality evidence from RCTs, and this is insufficient to decide whether combined treatment is beneficial in the management of Bell palsy. Further research is required to evaluate the efficacy of PT associated with SDT and to determine the better modality to reduce the time of recovery and occurrence of synkinesis. 


\section{REFERENCES}

1. Monini S, Lazzarino AI, Iacolucci C, et al: Epidemiology of Bell's palsy in an Italian Health District:

Incidence and case-control study. Acta Otorhinolaryngol Ital 2010;30:198-204

2. De Diogo-Sartre JL, Prim Espada MP, FernandezGarcia F: The epidemiology of Bell's Palsy (Spanish). Rev Neurol 2005;41:287-90

3. Weir AM, Pentland B, Crosswaite A, et al: Bell's palsy: The effect on self-image, mood state and social activity. Clin Rehabil 1995;9:121-5

4. Linder T, Bossart W, Bodmer D: Bell's palsy and herpes simplex virus: Fact or mystery? Otol Neurotol 2005;26:109-13

5. Stjernquist-Desatnik A, Skoog E, Aurelius E: Detection of herpes simplex and varicella-zoster viruses in patients with bell's palsy by polymerase chain reaction technique. Ann Otol Rhinol Laryngol 2006;115:306-11

6. Nunthavaj P, Thakkinstian A, Dejthevaporn C, et al: Corticosteroid and antiviral therapy for bell's palsy: A network meta-analysis. BMC Neurol 2011;11:1

7. Quant EC, Jeste SS, Muni RH, et al: The benefits of steroids versus steroids versus steroids plus antivirals for treatment of bell's palsy: A meta-analysis. BMJ 2009;339:b3354

8. Salinas RA, Alvarez G, Ferreira J: Corticosteroids for Bell's palsy (idiopathic facial paralysis). Cochrane Database Syst Rev 2009:CD001942

9. Gronseth G, Paduga R: Evidence-based guideline update: Steroids and antivirals for Bell palsy. Am Coll Neurol 2012;7:1-5

10. Teixeira LJ, Soares BGDO, Vieira VP, et al: Physical therapy for Bell's palsy (idiopathic facial paralysis). Cochrane Database Syst Rev 2011;12:CD006283

11. Pereira LM, Obara K, Dias JM, et al: Facial exercise therapy for facial palsy: Systematic review and metaanalysis. Clin Rehabil 2010;25:649-58

12. Ferreira M, Santos PC, Duarte J: Idiopathic facial palsy and physical therapy: An intervention proposal following a review of practice-Systematic review. Phys Ther Rev 2011;16:237-43

13. Peitersen E: Bell's palsy: The spontaneous course of 2,500 peripheral facial nerve palsies of different etiologies. Acta Otolaryngol Suppl 2002: 4-30

14. Shafshak TS: The treatment of facial palsy from the point of view of physical and medicine rehabilitation. Eura Medicophys 2006;42:41-7

15. House JW, Brackmann OF: Facial nerve grading system. Arch Otolaryngol Head Neck Surg 1985;93:146-7

16. Evans RA, Harries ML, Baguley DM, et al: Reliability of the House and Brackmann grading system for facial palsy. J Laryngol Otol 1989;103:1045-6

17. Allen D, Dunn L: Aciclovir or valaciclovir for Bell's palsy (idiopathic facial paralysis) (review). Cochrane Database Syst Rev 2009;2:CD001869
18. Sullivan FM, Swan IR, Donnan PT, et al: Early treatment with prednisolone or acyclovir in Bell's palsy. N Engl J Med 2007;357:1598-607

19. Ross BG, Fradet G, Nedzelski JM: Development of the sensitive clinical facial grading system. Otolaryngol Head Neck Surg 1996;114:380-6

20. National Library of Medicine: Medical subjects headings, 2010. USA National Library of Medicine, Maryland. Available at: http:/www.nhm.nib.gov/cgi/ mesh/2010/MB_cgi. Accessed February 2010

21. National Health Medical Research Council: $N H M R C$ Additional Levels of Evidence and Grades for Recommendations for Developers of Guidelines. Canberra, Australia, National Health Medical Research Council, 2009

22. Sherrington C, Herbert RD, Maher CG, et al: PEDro: A database of randomized trials and systematic reviews in physiotherapy. Man Ther 2000;5:223-6

23. Maher CG, Sherrington C, Herbert RD, et al: Reliability of the PEDro scale for rating quality of randomized controlled trials. Phys Ther 2003;83: $713-21$

24. Flores PF, Zazueta RM, García LH: Tratamiento de la paralisis facial periferica idiopatica: Terapia física versus prednisona. Rev Med Inst Mex Seguro Soc 1998;36:217-21

25. Tanovic E: Influence of early physiotherapy to recovery after paresis. $N$ Facialis Health Med 2009; 3:61-5

26. Tofolla E, Bossi D, Buonocori M, et al: Usefulness of BFB/EMG in facial palsy rehabilitation. Disabil Rehabil 2005;27:809-15

27. Yeo SG, Lee YC, Park DC, et al: Acyclovir plus steroid vs steroid alone in the treatment of Bell's palsy. Am J Otolaryngol 2008;29:163-6

28. Nicastri M, Mancini P, De Seta D, et al: Efficacy of early physical therapy in severe Bell's palsy: A randomized controlled trial. Neurorehabil Neural Repair 2013;17:542-51

29. Barbara M, Antonini G, Vestri A, et al: Role of Kabat physical rehabilitation in Bell's palsy: A randomized trial. Acta Otolaryngol 2010;130:167-72

30. Penteado TC, Testa JRG, Antunes ML, et al: Évaluation de la technique Chevalier pour la prévention des séquelles dans la paralysie faciale périphérique. Kinesither Rev 2009;90:40-7

31. Alakram P, Puckree T: Effects of electrical stimulation on House-Brackmann scores in early Bell's palsy. Physiother Theory Pract 2010;26:160-6

32. Beurskens $\mathrm{CH}$, Heymans PG: Positive effects of mime therapy on sequelae of facial paralysis: Stiffness, lip mobility, and social and physical aspects of facial disability. Otol Neurotol 2003;24:677-81 
33. Hato N, Yamada H, Kohno H, et al: Valacyclovir and prednisolone treatment for Bell's palsy: A multicenter, randomized, placebo-controlled study. Otol Neurotol 2007;28:408-13

34. VanSwearingen JM, Brach JS: Changes in facial movement and synkinesis with facial neuromuscular reeducation. Plast Reconstr Surg 2003;111: 2370-5

35. Coulson SE, Adams RD, O'Dwyer NJ, et al: Physiotherapy rehabilitation of the smile after long-term facial nerve palsy using video self-modeling and implementation intentions. Otolaryngol Head Neck Surg 2006;134:48-55

36. Beurskens $\mathrm{CH}$, Heymans PG: Mime therapy improves facial symmetry in people with long-term facial nerve paresis: A randomised controlled trial. Aust $J$ Physiother 2006;52:177-83

37. Beurskens CH, Heymans PG, Oostendorp RA: Stability of benefits of mime therapy in sequelae of facial nerve paresis during a 1-year period. Otol Neurotol 2006;27:1037-42

38. Dalla Toffola E, Bossi D, Buonocore M, et al: Usefulness of BFB/EMG in facial palsy rehabilitation. Disabil Rehabil 2005;27:809-15

39. Manikandan N: Effect of facial neuromuscular reeducation on facial symmetry in patients with Bell's palsy: A randomized controlled trial. Clin Rehabil 2007;21:338-43

40. Schwartz GE: Biofeedback and the behavioral treatment of disorders of disregulation. Yale J Biol Med 1979;52:581-96

41. Diels JH: New concepts in nonsurgical facial nerve rehabilitation. Otolaryngol Head Neck Surg 2000;9: 289-311

42. Diels JH: Facial paralysis: Is there a role for a therapist? Facial Plast Surg 2000;16:361-4

43. Shumway-Cook A, Woollacott JH: Motor Control: Translating Research Into Clinical Practice, ed 4. Baltimore, Lippincott Williams \& Wilkins, 2011

44. VanSwearingen J: Facial rehabilitation: A neuromuscular reeducation, patient-centered approach. Facial Plast Surg 2008;24:250-9

45. Gilden D: Treatment of Bell's palsy_-The pendulum has swung back to steroids alone. Lancet Neurol 2008;7:976-7 